\title{
RICOEUR E HEIDEGGER: A HERMENÊUTICA ONTOLÓGICA DO AGIR HUMANO
}

Ricoeur and Heidegger: the onthological hermeneutics of human action

DIOGO FILIPE MOURA ${ }^{1}$

\begin{abstract}
RESUMO: Este trabalho visa apresentar a tentativa feita por Ricoeur em sua obra Si mesmo como um outro de aproximar suas interpretações das de Heidegger no que se refere às leituras da filosofia aristotélica. O objetivo de Ricoeur é extrair dessa aproximação um entrecruzamento fecundo entre o conceito de preocupação (Sorge) em Heidegger com termos da filosofia de Aristóteles, como os conceitos de ato e potência para verificar a possiblidade de que possa surgir daí uma teoria da unidade analógica do agir a partir da preocupação heideggeriana. Pretendemos mostrar com essa exposição que os termos heideggerinos guardam, a partir da interpretação de Ricoeur, elementos de ligação com o aristotelismo.
\end{abstract}

Palavras-chave: Ato. Potência. Ipseidade. Preocupação. Agir

\begin{abstract}
This paper presents an attempt by Ricoeur himself in his work as another approaching their interpretations of Heidegger in relation to the readings of Aristotle. The goal of this approach is to extract Ricoeur an interaction between the fruitful concept of concern (Sorge) in accordance with Heidegger's philosophy of Aristotle, as the concepts of act and potency to verify the possibility that there may arise a theory of action from Heidegger's concern. We intend to show with this exhibition that Heideggerian terms keep, from the interpretation of Ricoeur, connecting elements with Aristotelianism.
\end{abstract}

Key words: Act. Potency. Selfhood. Concern. Acting

\section{INTRODUÇÃO}

Analisar a aproximação teórica entre o pensamento de dois filósofos não é uma tarefa fácil, ainda mais se tratando de dois dos maiores do século XX, Paul Ricoeur (1913-2005) e Martin Heidegger (1889-1976). Neste trabalho, dado a partir da obra O si mesmo como um outro (1990), pretendemos analisar a retomada que Ricoeur faz da filosofia aristotélica, mais precisamente, dos conceitos de ato e potência, e expor sua comparação com alguns conceitos de Heidegger, especialmente o de preocupação (Sorge). Este termo central para a compreensão da fatualidade do Dasein ${ }^{2}$ aparece, em algumas traduções, como cuidado ou cura ${ }^{3}$. Aqui seguiremos como aparece na tradução feita por Luci Moreira César de Sôi meme comme un autre, obra onde Ricoeur aproxima suas apropriações da filosofia aristotélica das de Heidegger a fim de extrair

\footnotetext{
${ }^{1}$ Mestre pelo Programa de Pós Graduação em Ética e Epistemologia - PPGEE-UFPI Universidade Federal do Piauí 2 Termo da filosofia de Heidegger usado para exprimir o ser mesmo que somos existindo, dados na fatualidade do mundo da vida.

${ }^{3}$ É a tradução do termo alemão Sorge oferecida por Márcia Schubach em Ser e tempo, Petrópolis. Ed. Vozes 3 edição. 2002.
} 
uma noção de si mesmo, implícita no Dasein, distinta de uma mesmidade, que possa configurar uma práxis. Essa tarefa visa acompanhar se há a possibilidade de se extrair um agir de características ontológicas (práxis) a partir do conceito de preocupação (Sorge) em Ser e tempo de Heidegger sob o prisma de sua hermenêutica da facticidade, e que possa ser identificada à noção do si, ou seja, da ipseidade rumo ao que o filósofo francês chamou de unidade analógica do agir.

A aproximação se torna possível pelo fato de Ricoeur trabalhar as categorias de ato e potência identificando-as a outro conceito aristotélico na sua tarefa de busca do si (ipseidade), o conceito de energéia-dynamis. Ao final, veremos o diagnóstico do próprio Ricoeur quanto à tentativa de se pensar a alteridade a partir da ipseidade no pensamento de Heidegger.

\section{HERMENÊUTICA, O OUTRO E O SI MESMO}

Em Si mesmo como o outro, Paul Ricoeur aborda o conceito de atestação. A atestação fornecerá a hipótese "segundo a qual a distinção entre ipseidade e mesmidade tem por objeto não somente duas constelações de significações, mas dois modos de ser" (RICOEUR,1993, P. 361). Assim, está instalada a aproximação entre a ipseidade e o modo de ser que somos o Dasein. A partir de uma releitura dos conceitos de ato e potência extraídos da Metafísica de Aristóteles, o filósofo francês se questionará sobre a possibilidade de uma hermenêutica ontológica fundada sob estas duas categorias que sirva de explicação para a questão sobre o que é o outro diante de mim mesmo e se perguntar pelo ser do si.

A essas três fontes de perplexidade - determinação circular do ato e da potência, esquartejamento de seus campos respectivos de aplicação (física do movimento de um lado, cosmoteologia do repouso e do pensamento do pensamento, por outro lado), primado do ato sobre a potência em ligação com a teoria da substância- acrescenta-se uma perplexidade específica concernente à relação dessa acepção primitiva do ser com o agir humano. A esse ponto que toda nossa empreitada diz respeito diretamente (RICOEUR, 1991, p. 368).

Para a empreitada, Ricoeur vai optar como recurso estratégico a definição que o termo atestação irá lhe dar no sentido de abarcar a concretude da dimensão da práxis, e isso o levará a outra questão, a saber, se a estrutura da atestação, "por ser um engajamento ontológico" (Ibidem p. 348) servirá de ponto de partida para o alcance fundamental da distinção entre ipseidade e mesmidade. Assim, vai se perguntar se é possível extrair o que chamou de uma unidade analógica do agir a partir da dissecação das duas categorias aristotélicas de ato e potência, utilizadas em sua Metafísica, meditações que abrangiam questões acerca do Ser e, especificamente, sua relacão com os entes que se dá na definição do conceito de ousía ${ }^{1}$.

${ }^{1}$ N.A. Termo grego traduzido pelos latinos por substância. Indicava Aristóteles determina o ser como ousia (substância), um composto de matéria-forma, em que a matéria atualiza sua potencialidade final em uma forma. 
A unidade analógica do agir está diretamente ligada ao importante conceito de atestação no pensamento de Ricoeur. Daí, pensa o filósofo francês que a reapropriação das categorias de ato e potência de Aristóteles poderão conectar a investigação do ser do si a uma práxis que seja um agir fundado ontologicamente. Essa dimensão leva à pergunta fundamental e globalizante sobre a estrutura dialética específica dada entre ipseidade, mesmidade e alteriadade, que apresentaremos como sendo uma estrutura análoga à apresentada por Heidegger em Ser e Tempo.

As análises de Ser e tempo de Heidegger emergem como a utilização benéfica da distinção entre consciência moral, valorativa (Gewissein) e consciência no sentido fenomênico (Bewusstsein), que veremos mais adiante, e da comparação que surge entre termos heideggerianos e aristotélicos, que ao final do texto surgirá sob a forma da conclusão de Ricoeur sobre a efetivação de uma hermenêutica do agir ontológico. O diálogo com Heidegger se dá porque este filósofo faz também uma releitura das categorias de Aristóteles afim de reinterpretar algum sentido encoberto pelos anos de tradição e de variadas leituras por parte de muitos autores. Heidegger, à época de Ser e tempo, pensava fazer uma hermenêutica da faticidade ${ }^{1}$ como recurso estratégico para sua ontologia "a expressão hermenêutica pretende indicar o modo unitário de abordar, concentrar, acessar a ela, isto é, de questionar a facticidade” (HEIDEGGER, 2012, p. 15)

O que será de comum entre os dois pensadores é que Ricoeur contestará a insuficiência da dimensão epistêmica para o debate em torno da dimensão alética, Heidegger, que o conceito tradicional de verdade assertórica aos moldes da lógica clássica não alcançam a dimensão da alétheia (desvelamento), palavra que recupera da língua grega para apontar uma dimensão originária em que o fenômeno da verdade se dava, palavra que serve ao predicado alético, dado por Ricoeur.

alétheia é perguntar pela essência (wesen) do próprio ser. E perguntar pela essência do ser é buscar a sua própria verdade. Falar de alétheia é falar da verdade do ser, pois "no einai, presentar-se, fala propriamente a alétheia, o desvelar-se". Ser (einai) é compreen-dido como "o que dá presença”. (HEIDEGGER, 1996, p. 254).

O filósofo francês aponta que a constatação da dimensão alética surge de um atopos ${ }^{2}$ do qual se pensava distinto da posição do cogito como certeza ${ }^{3}$. Ricoeur parte da análise do cogito para diferenciar a problemática da ipseidade das filosofias subjetivistas. "Ora, a caracterização alética da atestação não se limita a uma tal determinação epistêmica” (RICOEUR, 1991 P. 350). Portanto, a distinção aristotélica derivada do ato e potência entre ser-verdadeiro e ser-falso fica segundo ele, prisioneira de um lado, da "preeminência presumida do julgamento assertivo da apophansis, na ordem veritativa, e por outro lado, de uma metafísica cuja reapropriação é, senão,

\footnotetext{
${ }^{1}$ N.A. Projeto de Heidegger que visava a análise fenomenológica radical do Dasein em sua concretude ou, faticidade.

${ }^{2}$ Cf. RICOEUR, Paul. Si mesmo como o outro p. 350

${ }^{3}$ Cf. IDEM. P. 350
} 
impossível, pelo menos, extremamente difícil de arriscar" (RICOEUR, 1991, p. 353). A atestação, segundo Ricoeur, dá-se no âmbito contrário à suspeição ${ }^{1}$, mas que não é o equivalente à disjunção da lógica clássica entre ser-falso e ser-verdadeiro. A essa dialética na hermenêutica ontológica de Ricoeur significa que: "A suspeição é também o caminho para a travessia na atestação" (RICOEUR, 1991, p.353)

Mas o que significa então a atestação? Ou, melhor perguntando, o que a atestação atesta? Nesse ponto Ricoeur define a estrutura da atestação como ipseidade, ao mesmo tempo na sua diferença com respeito à mesmidade e na sua relação dialética com a alteridade. Entram em cena, novamente, as categorias de ato e potência para exemplificar a relação da alteridade, e de onde partem algumas dificuldades. Para Ricoeur, o necessário para uma ontologia da ipseidade é que esteja descentrada de um fundo de ato e potência para que se aponte a centralidade do agir humano. Para isso, se serve dos conceitos derivados de energéia-dynamis encontrados juntos ao de ato e potência. "O essencial é o próprio descentramento para baixo e para o alto, em Aristóteles a favor do qual a energéia-dynamis assinala para um fundo de ser ao mesmo tempo poderoso e efetivo, sobre o qual se destaca o agir humano" (Ricoueur, p. 360). Declara que se uma ontologia da ipseidade é possível pelo fato de possuir um fundo a partir do qual o si pode ser considerado agente. Centralidade do agir e descentramento em direção a um fundo de ato e potência, são esses dois traços igual e conjuntamente constitutivos de uma ontologia da ipseidade em termos de ato e potência (RICOEUR, 1991, p. 360).

Neste ponto de nosso texto, verificaremos a análise de Ricoeur das leituras de Heidegger sobre Aristóteles sob o prisma de sua própria reconstrução do par ato e potência ou, energéiadynamis e seu entrecruzamento com a Sorge (preocupação) heideggeriana para uma definição do si. O que importa a Ricoeur é o ultrapassamento da noção de Energéia-dynamis, vista da perspectiva do puro fazer e do puro operar, por uma visão a partir de sua aplicação aos diversos campos do agir humano, que é quando a energéia- dynamis irriga campos de aplicação diferentes do agir humano que ela manifesta sua fecundidade ${ }^{2}$.

\section{GEWISSENE BEWUSSTEIN}

Ricoeur acha muito fecunda a diferença apontada por Heidegger entre Gewissen e Bewusstein para assinalar a distinção entre consciência moral e consciência no sentido fenomênico, para poder saber se as categorias que analisa no decorrer do livro possuem estatuto ontológico, ou seja, se são originárias. Ao trabalhar tal distinção, Ricoeur visa a atestação da consciência para

${ }^{1}$ Cf.Idem p. 353

2 Cf. Idem. P. 360. 
a garantia da análise. A distinção entre boa e má consciência, significa atestação (Bez̨ugung) como aponta "a diferença me ajuda a fazer a distinção entre ipsidade e mesmidade ${ }^{1}$. Ricoeur aponta que para Heidegger há uma "dependência entre a ipseidade e o modo de ser que somos a cada vez, enquanto, para este ser esta em seu próprio ser a saber o Dasein" (RICOEUR, 1991, p. 361). Essa é a maneira de ser no mundo que a ipseidade figura entre os existenciais. Desse modo "O estatuto ontológico da ipseidade é, desse modo, solidamente fundado sobre a distinção entre os dois modos de ser que são o Dasein e a Vorbandeheit” (RICOEUR, 1991, p. 362). Este ponto foi assinalado mais acima através do entrecruzamento entre o Dasein e a Vorhandheit, que proporcionará a Ricoeur fazer a correlação entre ipseidade e Dasein. "na maior parte das vezes e antes de tudo, Dasein se entende a partir de seu mundo, e a Co-existência dos outros vem ao encontro nas mais diversas formas, a partir do que está à mão dentro do mundo". (HEIDEGGER, 2008, p.171)

Podemos inferir já a antecipação da pergunta por uma práxis ontológica própria ao pensamento de Heidegger que será posta em questão por Ricoeur, o que já é a pergunta por uma ética. Na reapropriação de Aristóteles, se faz pertinente o questionamento junto a conceitos heideggerianos como si-mesmo, preocupação e ser-no-mundo para que se apreendam os conceitos centrais de Ser e tempo. "A investigação que se dirige ao fenômeno, capaz de responder à questão do quem, conduz às estruturas do Dasein que, junto ao ser-no-mundo são igualmente originárias, a saber, o ser-com e a co-presença” (HEIDEGGER, 2008, p. 169) e "o esclarecimento do Ser-no mundo, mostrou que, de início, um mero sujeito não 'é' e nunca é dado sem mundo. Da mesma maneira, também de início, não é dado um eu isolado sem outros” (heidegger, 2008, p. 167). Ricoeur não se lança ao desafio sem antes advertir que se trata de uma empreitada repleta de ciladas, pois "se trata de interpretar ontologicamente minha própria hermenêutica do si, servindome da reapropriação heideggeriana de Aristóteles.” (RICOEUR, 1991, p. 364)

Para Ricoeur, o entrecruzamento entre Dasein e ipseidade se dá na noção de preocupação (Sorge). O sentido desse termo para Heidegger era "a analítica do Dasein que conduz ao fenômeno do cuidado (que) deverá preparar a problemática ontológica fundamental, isto é, a questão do sentido do ser em geral” (HEIDEGGER, 2008, P. 249) o que se dá constitui um existencial, segundo o autor, mais fundamental. Para Ricoeur²: "A preocupação aparece assim como o fundamento da antropologia filosófica em Ser e Tempo, antes que a ontologia seja orientada para além de toda antropologia filosófica pela noção de temporalidade”. A questão fundamental para Ricoeur junto ao pensamento de Heidegger é saber se a Sorge pode ocupar o lugar do agir, ou seja, da práxis ontológica na empreitada de Ricoeur. Não se esgotando a partir de

${ }^{1}$ Idem. P. 361

2 Idem. P. 362 
determinações linguísticas, nem práxicas nem narrativas (RICOEUR, 1991 p. 367), nem éticomorais, o agir visado por Ricoeur pode ser analisado e posto em comparação com o lugar que ocupa a Sorge heideggeriana, lançando a pergunta se a preocupação (Sorge) seria suficientemente equivalente ao que chamamos de unidade analógica do agir? (RICOEUR, 1991, p. 367).

Em sua releitura de Aristóteles, analisando as leituras de Heidegger Ricoeur enxergou as seguintes possibilidades, em suas palavras:

Desse modo, a aproximação entre a Sorge segundo Heidegger e a práxis segundo Aristóteles, pode dar lugar a uma inteligência aprofundada num e noutro conceito. Por minha parte, estou a esse respeito tanto mais atento, que é o conceito aristotélico de práxis que me ajudou a ampliar o campo para além da noção estreita de ação nos termos da filosofia analítica. Em troca, a Sorge heideggeriana dá à práxis aristotélica um peso ontológico que não parece ter sido a intenção de Aristóteles (RICOEUR, 1991, p. 364).

Vários comentadores sugerem a possibilidade de uma comparação dos termos heideggerianos aos de Aristóteles, mas o que interessa a Ricoeur é justamente a ampliação da noção de práxis juntamente à perspectiva da preocupação como categoria aberta ao Dasein que, como apontado acima, não parece bem ter sido objeto das considerações de Aristóteles na sua ética, o que é um problema, segundo o próprio Ricoeur, que surge no horizonte da sua hermenêutica dos textos de Aristóteles. A questão dentro da relação feita entre práxis e Sorge é se a noção de ser-no-mundo pensada como o si mesmo pode ser análoga à energéia. A constatação é que não se pode fazer uma comparação entre energéia e presença (Dasein) como seu correlato imediato. Para a constituição da ontologia da ipseidade, é fundamental que se ponha a centralidade do agir e se leve em conta o descentramento em direção "a um fundo de ato e potência e seria preciso fazer da presença o nexo fundamental entre o ser si-mesmo e o ser-no-mundo?” (Heidegger, 2008, p. 367)

Surge a questão se o ser-no-mundo pode ser o "não-pensado" da energéia, mas isso não traz tantos problemas quanto aliar energéia à faticidade. À ontologia de Ricoeur, é próprio que a concebamos a partir de uma tensão entre potência e efetividade que parece se apagar na equação entre energéia e faticidade ${ }^{1}$. Eis a ruptura com as interpretações de Heidegger junto a Aristóteles. Pondo o problema sobre a impossibilidade do Dasein sair da vinculação do "sempre já"2 se não se estaria sob o risco de atenuar a dimensão da energéia-dynamis em virtude da qual nosso agir nos empurraria a permanecer enraizados no ser ${ }^{3}$. Ricoeur afirma que a "decepção" da empreitada de interpretar Aristóteles e tentar cruzá-la com as leituras aristotélicas de Heidegger carece da possibilidade de se comparar uma ontologia às categorias de ato e potência em termos de práxis.

${ }^{1}$ Cf. Ibid, p. 368.

${ }^{2}$ Cf. Ibidem.

${ }^{3}$ Cf. Ibidem. 
Isso leva a consequência, explorada mais à frente em Si mesmo como um outro, de Heidegger não ter pensado a carnalidade como constitutivo ontológico.

\section{CONCLUSÃO}

Concluímos que a tentativa de Ricoeur de cruzar suas interpretações de Aristóteles com as de Heidegger nos oferece um panorama dos conceitos fundamentais em que são trabalhados as noções principais da fenomenologia voltadas à práxis do mundo. A reapropriação de importantes conceitos aristotélicos segue a linha de elucidação do fenômeno do agir humano em suas variadas manifestações, em sua concretude diante do mundo, e, pensa diretamente uma ética. Diante da constatação da impossibilidade da filosofia de Heidegger oferecer uma viés onde se pensasse a ipseidade e sua relação profunda com a alteridade, Ricoeur não recua e parte, durante o decorrer de Si mesmo como um outro parte para interpretações e diálogos com diversos filósofos afim de que pense o problema ético que a alteridade e a ipseidade inspiram sob a ótica da atestação, o crédito imediato da faticidade dada a cada um que somos no sermos juntos no mundo. A hermenêutica de Ricoeur nos oferece uma riqueza de possibilidades dentro da interpretação de textos filosóficos que nos permitem continuar a avançar rumo às respostas das questões que se impõe.

\section{REFERÊNCIAS}

HEIDEGGER, Martin. Ser e Tempo. Petrópolis: Vozes, 2002.

. A tese de Kant sobre o ser. São Paulo. Os Pensadores. Abril Cultural, 1996.

. Ontologia: hermenêutica da faticidade. Petrópolis. Vozes, 2012

RICOEUR, Paul. O si-mesmo como um outro. Trad. Luci Moreira Cesar. Campinas: Papirus, 1991. 